\title{
A Percepção de Educadores Indígenas Sobre Meio Ambiente: Uma Breve Análise
}

\author{
The Perception of Indigenous Educators on the Environment: The Brief Review
}

\author{
Albanice de Souza Ramos' \\ Carlos Alexandre Santos Querino" \\ Eulina Maria Leite Nogueira"II \\ Renato Abreu Limalv
}

\section{Resumo}

A percepção ambiental configura-se como uma ferramenta essencial para a compreensão do comportamento humano em relação ao ambiente e para o planejamento de ações que promovam a sensibilização e o desenvolvimento de posturas éticas e responsáveis perante o local em que vivem. As discussões em torno da percepção ambiental têm se destacado nos últimos anos. Com isso, a presente pesquisa tem como objetivo compreender a percepção ambiental de docentes indígenas apresenta sobre meio ambiente com a sua cultura e com a educação. A referida pesquisa fundamenta-se numa abordagem qualitativa por ser tratar de um artigo de revisão. O trabalho foi realizado através de pesquisas descritiva e exploratória que visa analisar o material produzido nos trabalhos científicos obtido nas plataformas SCIELO, Google acadêmico, PubMed, MEDLINE e LILACS. Para a realização da seleção final das obras foram feitas leituras sobre cada uma das publicações com a intenção de averiguar-se a pertinência de cada um dos estudos para com a questão norteadora. Utilizaram-se as seguintes combinações de palavras-chave: educadores ambientais, educação indígena, percepção ambiental e meio ambiente. De acordo com os termos de busca, foi possível acessar centenas de pesquisas científicas, entre teses, dissertações e artigos. Com base nos resultados obtidos, verificou-se que os professores indígenas adquirem conhecimentos, valores e ações de sensibilização frente às questões ambientais. Diante disso, percebe-se que a necessidade da construção de projetos mais eficazes de parcerias para que ocorram significativas trocas, onde haja reconhecimento e valorização desses conhecimentos.

Palavras-chave: Percepção Ambiental; Preservação; Conhecimento; Natureza

\section{Abstract}

Environmental perception is an essential tool for understanding human behavior in relation to the environment and for planning actions that promote awareness and development of ethical and responsible positions in the place where they live. Discussions around environmental perception have been prominent in recent years. With this, the present research aims to understand the environmental perception of indigenous teachers present about the environment with their culture and education. This research is based on a qualitative approach because it is a review article. The work was carried out through descriptive and exploratory research that aims to analyze the material produced in the scientific works obtained in the platforms SCIELO, Google academic, PubMed, MEDLINE and LILACS. For the final selection of the works, readings were made on each of the publications with the intention of ascertaining the relevance of each of the studies to the guiding question. The following keyword combinations were used: environmental educators, indigenous education, perception environment and the environment. According to the search terms, it was possible to access hundreds of scientific researches, between theses, dissertations and articles. Based on the results obtained, it was verified that indigenous teachers acquire knowledge, values and actions to raise awareness about environmental issues. Given this, it is perceived that the need to build more effective projects of partnerships so that significant exchanges occur, where there is recognition and appreciation of this knowledge.

Keywords: Environmental Perception; Preservation; Knowledge; Nature

\footnotetext{
Pedagoga, Mestranda pelo Programa de Pós-Graduação em Ciências Ambientais pela Universidade Federal do Amazonas,AM - Brasil. E-mail:albanice.ramos25@gmail.com

" Meteorologista, Prof. Adjunto da Universidade Federal do Amazonas - UFAM, vinculado Instituto de Educação Agricultura e Ambiente - IEAA e ao

Programa de Pós-graduação em Ciências Ambientais, AM - Brasil. E-mail: carlosquerino@ufam.edu.br

III Possui graduação em Licenciatura em Estudos Sociais pela Universidade Federal do Amazonas, AM - Brasil. E-mail: eulinanog@hotmail.com

` Biólogo; Pós-graduado em Gestão Ambiental; Mestre em Meio Ambiente e Doutorando em Biodiversidade e Biotecnologia pela Universidade Federal do Amazonas. Departamento de Ciências Biológicas, AM - Brasil. E-mail: renatoabreu07@hotmail.com
} 


\section{Introdução}

De maneira a iniciar esta discussão, torna-se indispensável buscar, historicamente, quais acontecimentos promoveram a mudança de percepção da humanidade para com a temática ambiental, por meio da evolução das políticas públicas e decisões em âmbito mundial a respeito das questões ambientais (POTT; ESTRELA, 2017). Conforme destacam os estudos de Siqueira (2008), os problemas ambientais são percebidos e interpretados de diferentes maneiras, uma vez que as pessoas encaram os problemas de acordo com as peculiaridades de suas percepções.

Partindo desse pressuposto, torna-se necessário entender como os indivíduos reagem às questões como: sensação e percepção para compreender porque assumem certos comportamentos, visto que pessoas distintas podem perceber a mesma situação de modos diferentes.

De acordo com Marczwski (2006), a percepção ambiental configura-se como uma ferramenta essencial para a compreensão do comportamento humano em relação ao ambiente e para o planejamento de ações que promovam a sensibilização e o desenvolvimento de posturas éticas e responsáveis perante o local em que vivem.

Atualmente, a relação do ser humano com o ambiente natural é uma preocupação necessária ao quadro ambiental e social, assim se faz necessário o estudo da percepção ambiental, pois assim é possível a realização de um trabalho partindo da realidade do público alvo, para conhecer como os indivíduos percebem e interagem com o meio ambiente em que convivem, suas fontes de satisfação e insatisfação (FAGGIONATO, 2007).

Diante disso, Faggionato (2016) elucida que a percepção ambiental é o conhecimento ou a tomada de consciência do ser humano no ambiente em que está inserido e isto não relaciona somente a parte biológica entre si, mas também a Psicologia, a Geografia, a Antropologia e outras ciências que interagem umas às outras.

Assim, o desenvolvimento da prática de Educação Ambiental (EA) torna-se efetiva com a participação dos educadores uma vez que estes estejam preparados para utilizar as técnicas adequadas de ensino. Desse modo, a EA está intrinsicamente relacionada com a prática da tomada de consciência e a ética que conduzem para a melhoria da qualidade de vida. Contudo, é necessária a compreensão da totalidade do ambiente o que nos permite trabalhar a EA de forma transdisciplinar reunindo assim conhecimentos multidimensionais, visando sempre soluções para combater os problemas ambientais. Nesse sentido, a presente pesquisa tem como objetivo compreender a percepção ambiental de docentes indígenas apresenta sobre meio ambiente com a sua cultura e com a educação.

\section{Metodologia}

Neste trabalho foi realizada uma revisão de literatura, através de uma pesquisa descritiva e exploratória que visa analisar o material produzido nos trabalhos científicos considerando todas as etapas como: conceitos, técnicas, resultados, discussões e conclusões, com intuito de verificar artigos publicados em periódicos nacionais e internacionais, compreendendo o período de inclusão 1967-2018, visto que este tipo de estudo procura explicar um problema a partir de referências teóricas publicadas em documentos.

De acordo com Gil (2008) a pesquisa de caráter bibliográfico desenvolve-se com trabalhos já elaborados de livros e artigos por um processo sistemático através do método da cientificidade, tendo como objetivo fundamental expor soluções de problemas ao emprego de procedimentos científicos.

Marconi; Lakatos (2003) complementam ainda mais as ideias do autor supracitado, afirmando que a finalidade da pesquisa bibliográfica é colocar o pesquisador em contato direto com tudo que foi escrito, dito ou filmado sobre determinado assunto, inclusive conferências seguidas de debates que tenham sido transcritas por alguma forma, quer publicados ou quer gravados.

O estudo bibliográfico oferece mecanismo para definir/ resolver problemas já conhecidos, mas também explorar problemas desconhecidos que não se cristalizaram suficientemente permitindo ao pesquisador melhor análise de pesquisas e o manuseio dos resultados, ou seja, a pesquisa bibliográfica não é repetição de dados já existentes mas, sim o que já foi dito ou escrito sobre determinado assunto, proporcionando um novo enfoque ou abordagens chegando a resultados inovadores (MARCONI; LAKATOS, 2003).

Sendo assim, o levantamento bibliográfico foi feito por meio de consulta eletrônica nas plataformas eletrônicas Google acadêmico, Scientific Electronic Library Online (SCIELO), PubMed, Literatura Latino-americana e do Caribe em Ciências da Saúde (LILACS) e MEDLINE (Literatura Internacional em Ciências da Saúde), acessadas por meio da Biblioteca Virtual em Saúde (BVS). Utilizaram-se as seguintes combinações de palavras-chave: educadores ambientais, educação indígena, percepção ambiental e meio ambiente. $\mathrm{O}$ método histórico subsidiará a investigação dos acontecimentos bibliográficos e documentais que influenciam o problema no presente.

De acordo com os termos de busca, foi possível acessar centenas de pesquisas científicas, entre teses, dissertações e artigos. Como próximo passo, iniciou-se a leitura dos títulos, sendo selecionados somente os artigos científicos, pela atualidade que representam em termos de pesquisa.

Esta etapa da pesquisa é relevante, podendo conhecer trabalhos realizados a respeito do tema estudado, se embasar teoricamente e até adquirir ideias novas, possibilitando ao pesquisador uma visão mais profunda a respeito do assunto, respondendo assim seus questionamentos. Além disso, utilizou-se a abordagem qualitativa e quantitativa.

Para se realizar a seleção final das obras foram lidos os resumos de cada uma das publicações com a intenção de averiguar-se a pertinência de cada um dos estudos para com a questão norteadora. A natureza da pesquisa se caracteriza como básica que se define a gerar conhecimento. Enquanto que os critérios de exclusão eram 
artigos que não abordavam as ideias principais a serem exposta no artigo.

\section{Resultados e Discussão}

\section{Percepção Ambiental}

As discussões em torno das questões ambientais têm sido consideradas cada vez mais urgentes, ou seja, a forma como o ser humano interage com o mundo, depende do seu conhecimento e de sua percepção em relação ao uso que ele faz dos recursos ambientais.

A EA está inserida nos Parâmetros Curriculares Nacionais (PCN's) das escolas, isto surgiu diante da preocupação com a formação de atitudes relacionadas a esta temática. A escola proporciona mudanças de atitudes de seus alunos com relação ao ambiente, pois, tem procurado através de diferentes disciplinas, proporcionarem informações relativas ao meio ambiente (VIEIRA; KALHIL; RUIZ, 2012).

Nesse sentido, Faggionato (2008) nos afirma que as interações entre ser humano e ambiente estão diretamente relacionadas às percepções, aos processos cognitivos, julgamentos e expectativas de cada indivíduo. Desse modo, o estudo da percepção ambiental é essencial para a compreensão das inter-relações entre ser humano e meio ambiente, suas expectativas e condutas.

Ainda convém lembrar que o estudo da percepção ambiental é de fundamental importância, pois possibilita ao homem a auto compreensão sobre os problemas ambientais, visto que é necessário conhecer e perceber as relações entre os grupos humanos e os ambientes naturais, assim a partir do momento que se conhece a realidade torna-se possível buscar soluções que venham minimizar os impactos ambientais que são resultados da própria ação humana (NOGUEIRA, et al., 2018).

É papel de o professor criar meios e condições para que os alunos desenvolvam capacidades de trabalho intelectual visando sua autonomia no processo de aprendizagem e independência de pensamento (LIBÂNEO, 1994). Para isso é preciso que o professor desenvolva a capacidade de descobrir as relações sociais reais implicadas em cada acontecimento, em cada matéria, em cada discurso.

Conforme relata Sato (2002), a percepção é importante para a construção e a formação de novos valores e condutas no espaço educacional, pois na compreensão da percepção ambiental dos atores sociais é possível conhecer e/ou identificar aspectos relacionados às relações: Homem - Sociedade - Natureza.

Todavia, o estudo de percepção ambiental, fornece dados, que podem subsidiar ações para que as pessoas se percebam no processo de interação e possam ser sensibilizadas e assim, gerar consciência. Dessa forma, constata-se a real importância de conhecer e perceber as relações entre os grupos humanos e os ambientes naturais. Assim, é imprescindível saber como os indivíduos com quem se tem interações profissionais e sociais percebem e interagem com o meio ambiente em que vivem.

No entanto, a observação da natureza é um fator muito importante quando se pretende trabalhar a percepção ambiental, principalmente das relações entre os seres humanos e os meios físicos e biológicos. Todavia, é através do estudo da percepção ambiental que podemos identificar as formas precisas em que a educação ambiental poderá sensibilizar conscientizar e trabalhar conjuntamente as dificuldades que os sujeitos-atores possam vir a ter quando forem apresentadas às questões ambientais (FORGUS, 1971; PENNA, 1982; FERREIRA, 1997; MORIN, 2000; DURKHEIM, 2009).

Nesse caso, os professores indígenas necessitam buscar "esse sentido" em sua comunidade, criar momentos para refletir e buscar soluções de problemas socioambientais locais. "A educação é uma forma de intervenção no mundo" (FREIRE, 1996, p. 38). É por meio da educação que se tem a tomada de consciência que consiste na "ação-reflexão" para daí modificar a realidade perturbante.

$\mathrm{Na}$ relação entre ambiente e qualidade de vida, admite-se o conceito de ambiente como sendo o espaço onde ocorrem as ações antrópicas, composta por suas dimensões físicas, sociais e culturais. Contudo, pode-se considerar e buscar entender como o meio ambiente influencia positivamente ou negativamente, o comportamento de um estilo de vida saudável, para possibilitar uma intervenção mais efetiva na criação de ambientes desejáveis e propícios para o desenvolvimento da atividade física e do lazer (REIS, 2001).

Não basta apenas criar e distribuir reservas ambientais, como os parques urbanos, mas deve-se atentar que seu objetivo maior é formar cidadãos conscientes e sensibilizados às questões ambientais, tanto locais quanto globais. O elo homem-meio ambiente exige responsabilidades; logo, o homem como integrante, deve sugerir e desenvolver atitudes necessárias para a conservação do conjunto de recursos naturais e patrimoniais que os cerca (VIANA et al., 2014).

Desta forma, o estudo da percepção ambiental torna-se oportuno para que possamos compreender melhor as inter-relações entre o homem e o ambiente no qual vive, suas expectativas, satisfações e insatisfações, valores e condutas, como cada indivíduo percebe, reage e responde diferentemente frente às ações sobre o meio. O estudo deve buscar não apenas o entendimento do que o indivíduo percebe, mas também promover a sensibilização, a consciência, bem como o desenvolvimento do sistema de compreensão do ambiente ao seu redor. Essa ferramenta de pesquisa é fundamental para os gestores públicos para que estes possam gerar subsídios para implementação de políticas e programas que envolverão a sociedade (VIANA et al., 2014).

Muitas mudanças ambientais citadas estão associadas com a cobertura do solo e com os recursos hídricos. Isto sugere que o maior número de citações de mudanças ambientais neste tema se dê em função da importância dos recursos destes ecossistemas para as comunidades que estão inseridas neste meio ambiente específico. Para o desmatamento, os agricultores também identificaram causas específicas e se percebem como parte do processo. Os habitantes locais indicam como causas dos desmatamentos o aumento dos assentamentos e as 
aberturas realizadas pelos agricultores familiares para sua subsistência (FATORELLI, 2013).

\section{Concepção Teórica sobre Percepção Ambiental}

Vive-se numa sociedade capitalista onde o consumismo dos dias atuais tem trazido várias consequências negativas tanto para o homem, como para a sociedade e o meio ambiente. Um dos papeis da escola, segundo Libâneo, "é assegurar o desenvolvimento das capacidades e habilidades cognitivas sobre a base dos conhecimentos científicos, que formam o pensamento crítico [...]" permitindo o domínio de métodos, técnicas e aplicação prática desses conhecimentos na vida escolar e prática social (LIBÂNEO, 1994, p. 45). Tendo a escola esse papel, há necessidade de estar atento a que tipo de EA se quer ou se deve praticar.

Em virtude disso, diversos autores (FORGUS, 1971; PENNA, 1982; FERREIRA, 1997; MORIN, 2000; DURKHEIM, 2009) passaram a realizar pesquisas referentes aos processos mentais relacionados à percepção, ou seja, buscando meios para compreender quais os fatores que levam os indivíduos a apresentarem percepções e comportamentos diferentes em relação ao meio ambiente. Piaget (1967) define percepção à medida que a diferencia de inteligência, e também aborda a distância como um de seus condicionantes. Na teoria Skinneriana, o conceito de percepção é explicado por meio do comportamento perceptivo, descrito como um comportamento complexo e que se inter-relaciona com muitos outros.

Para Marin (2008), a percepção tem sua origem do latim perception, é definido, em linhas gerais, como o ato ou efeito de perceber; a combinação dos órgãos sensoriais no reconhecimento de um objeto ou conjunto de elementos do ambiente; recepção de um estímulo; sensação; intuição; ideia; imagem; representação intelectual.

De acordo com Oliveira (2005), quando enunciamos o conceito de percepção do meio ambiente, queremos dizer como as pessoas percebem ativamente o meio ambiente, mais ainda, como as pessoas conhecem o meio ambiente [...], percebemos somente o que nossa mente atribui significado. A percepção é seletiva, exploratória, antecipadora. (OLIVEIRA, 2005).

Segundo Macedo (2000, p. 69), a percepção ambiental é considerada uma precursora do processo que desperta a conscientização do indivíduo em relação às realidades ambientais observadas. O conhecimento é um importante aspecto na compreensão da interação homem-natureza, fazendo-se então necessário o desenvolvimento do aprendizado que envolva elementos de ordem científica, ética e estética, e que essa interação seja explicitada e favoreça a conscientização ambiental, estimulando ações relativas à conservação da natureza.

Conforme os pensamentos de Rosa; Silva (2002), a percepção ambiental pode ser definida pelas formas como os indivíduos veem, compreende e se comunicam com o ambiente, considerando-se as influências ideológicas de cada sociedade. As respostas ou manifestações decorrentes desse contexto são resultados das percep- ções, individuais e coletivas, dos processos cognitivos, julgamentos e expectativas de cada pessoa.

Nesse sentido, Palma (2005) relata que, podemos também conceituar a percepção ambiental, como a capacidade de perceber o meio ambiente no meio em que nos encontramos, isto é, como aprendemos a cuidá-lo e protegê-lo da maneira mais adequada possível.

Desse modo, explorar e usufruir o meio ambiente são práticas do ser humano que busca prover os seus desejos, as suas necessidades, mas é necessário que se reflita criticamente sobre as consequências destas atitudes, especialmente em longo prazo, pois as nossas ações no meio ambiente construído ou natural podem afetar seriamente a qualidade de vida de gerações futuras.

Para Carvalho (2008), os educadores devem contribuir para essa atitude ecológica em sua prática educativa por meio da EA, formando sujeitos com a capacidade de compreender e agir, ler e interpretar, mudar a forma de ser e ver esse mundo em transformação.

\section{Fatores de Influência na Percepção Ambiental}

Nos primórdios do século XXI, o movimento entorna da diminuição dos impactos ambientais vem ganhando força, ou seja, cada vez mais o meio ambiente sofre de forma direta ou indiretamente com nossas ações, visto que são ações influenciadas por fatores socioeconômicos, políticos, sociais e culturais, que estão relacionados à insatisfação das pessoas em relação ao seu padrão de vida (WEIS, 2017).

Logo, a percepção ambiental pode ser utilizada para avaliar a degradação ambiental de uma determinada região ou comunidade local (FERREIRA, 2001). Assim, ressalta-se a importância deste estudo que propõe a visão da percepção ambiental de professores indígenas sobre o tema meio ambiente, uma abordagem interdisciplinar pautada pela prática e pela aproximação do tema a questões em que o aluno possa intervir como cidadão. Sendo necessário, desmistificar a Educação Ambiental que privilegia unicamente os grandes problemas ambientais globais para aproximá-la do cotidiano dos alunos, tornando-a menos teórica e disciplinar, já que se trata de um saber pertencente a todas as áreas do conhecimento.

Mediante a isso, compreende-se que cada pessoa percebe o meio, reage e responde de forma diferenciada, pois as respostas e manifestações são resultantes das percepções individuais. Nesse sentido, a EA é um tema transversal que segundo os PCN's visa fomentar a construção de um pensamento crítico e reflexivo perante a postura de degradação que o homem vem tomando ao longo da história moderna (BRASIL, 1997).

Dos problemas relativos à degradação progressiva do meio ambiente originam-se questionamentos acerca do direito ambiental, uma vez que identificar fatores prejudiciais, buscar soluções e fiscalizar tais procedimentos devem ser ações compartilhadas pelo Estado e pela coletividade. Nesse contexto, a educação ambiental apresenta-se não apenas para análise e correção de situações de risco já existentes, mas principalmente como forma 
de prevenir a degradação do ambiente em que vivemos. A abordagem interdisciplinar do tema é a concretização da verdade incontestável de que os cuidados com o meio ambiente são deveres de todos e todas (COLOMBO, 2014).

Pode-se afirmar que para manter a continuidade da vida humana é necessário manter a natureza com todas as riquezas na sua biodiversidade, o ser humano faz parte da natureza e quando ele a destrói está se destruindo também, contudo, há necessidade de mudança nesta forma de pensar e agir. Dessa maneira, torna-se imprescindível que as escolas de educação básica ofereçam atividades voltadas à EA onde esta fornece os meios de percepção e compreensão de vários fatores que interferem na qualidade do ambiente como um todo.

O pensamento crítico revela que o olhar perante a sociedade não pode ser apenas superficial, a educação surge como uma fonte transformadora dessa realidade onde o homem busca satisfazer suas necessidades acarretando assim sérios problemas ambientais e os educadores tem um papel estratégico e decisivo na inserção da educação ambiental no cotidiano escolar, qualificando os alunos para um posicionamento crítico face à crise socioambiental, tendo como horizonte a transformação de hábitos e práticas sociais e a formação de uma cidadania ambiental que os mobilize para a questão da sustentabilidade no seu significado mais abrangente (JACOBI, 2005).

Desse modo, a EA está intrinsicamente relacionada com a prática da tomada de consciência e a ética que conduzem para a melhoria da qualidade de vida. Contudo, é necessária a compreensão da totalidade do ambiente o que nos permite trabalhar a EA de forma transdisciplinar reunindo assim conhecimentos multidimensionais, visando sempre soluções para combater os problemas ambientais.

Nesse sentido, ressalta que:

Há uma necessidade de conscientização das pessoas em relação à problemática ambiental e as escolas são chamadas a contribuir nessa questão por meio de atividades voltadas a educação ambiental através das orientações contidas nos Parâmetros Curriculares Nacionais - Meio Ambiente - Saúde, referente às quatro primeiras séries da Educação Fundamental, que tem como objetivo auxiliar o professor no andamento de seu trabalho (PINHÃO; MARTINS, 2012).

Segundo Jacobi (2003), a EA é base fundamental para que ocorra uma modificação da crescente degradação socioambiental, através de uma intervenção entre culturas, comportamentos e interesses de grupos sociais para que ocorram as mudanças desejadas. Ela assume um papel transmutador, onde os indivíduos se tornam responsáveis a fim de promover o desenvolvimento sustentável.

O processo de ensino-aprendizagem dentro da questão da educação ambiental é de suma importância, pois, pode ajudar a transpor a enraização da cultura de degradação ambiental, a educação pode e deve vir contrapor o pensamento inconsciente do uso indiscriminado dos recursos naturais renováveis e não renováveis, dentro de um círculo vicioso de degradação e evitando um possível colapso ambiental, que seria a falta dos recursos naturais necessários para a permanência do homem do seu habitat natural no planeta Terra (NOGUEIRA et al., 2018).

Sendo assim a escola é um espaço de construção e formação de conduta social humana, na escola encontram-se todas as formas de expressão cultural e social advinda da sociedade como se fosse um reflexo subjetivo das ações humanas, a sociedade exercendo uma forte influência sobre a estruturação educacional, porém a escola é a única estrutura capaz de poder mudar os paradigmas sociais, libertar o sujeito do senso comum alienado, para o sujeito reflexivo e crítico das práticas sociais. Diante disso, a escola é um espaço de construção de cidadania aonde se pode ressignificar pedagogicamente a sensibilidade humana para a mudança positiva da realidade (NOGUEIRA et al., 2018).

\section{Percepção Ambiental e Cultura Indígena}

Ao longo do tempo, a evolução da humanidade acarretou uma série de problemas de cunho socioambiental, fato este que provocou impactos negativos que incidiram diretamente sobre os recursos naturais. A educação ambiental não pode ser ignorada, uma vez que ela se faz presente e acontece nas relações cotidianas, nos espaços das comunidades, nas escolas, e tem o papel fundamental como agente de formação, informação e transformação na valorização dos saberes, minimizando assim as diferenças existentes entre as raças, buscando um equilíbrio entre ser humano e natureza a partir da compreensão e sensibilização dessa inter-relação (OLIVEIRA, 2006).

Os educadores não podem ficar alheios às questões ambientais que as nossas cidades/escolas já estão enfrentando. A educação ambiental exerce um papel importante na escolarização, e preparação do estudante para a cidadania. As escolas existentes nas comunidades indígenas são frutos de uma parceria entre a própria comunidade e Secretaria Municipal de Educação (SEMED) (VIEIRA; KALHIL; RUIZ, 2012).

Embora o parecer 14/99 do Conselho Nacional de Educação garanta aos professores indígenas a formação e capacitação em serviço (BRASIL, 1999), o ideal seria que o professor indígena se formasse antes de iniciar sua atividade docente, mas não é o que ocorre, o que impossibilita ao professor fazer uma análise crítica de sua própria metodologia de ensino.

A partir da década de 90 , o modelo brasileiro de educação indígena ganhou força com a criação da Fundação Nacional do Índio (FUNAI) e com as Secretarias Estaduais e Municipais que adotaram as escolas rurais, urbanas e das missões religiosas, a fim de tornarem os índios bilíngues, leitores do evangelho trazido nas línguas maternas. Contudo, o ensino continuava distante da realidade dos índios.

No meio deste paradigma, surgiram as propostas de escolas voltadas para a formação dos professores indígenas, com currículos específicos. Tais escolas foram implantadas por associações, lideranças indígenas ou a partir de interlocução entre pesquisadores e comunidades indígenas. O ano de 1994 marca a data em que as Universidades Brasileiras aliam-se a organizações não 
governamentais e tomam a iniciativa de formular políticas voltadas para as questões indigenistas (SANTOS; ESTEVES; SILVA, 2013).

Diante disso, a EA desempenha um papel fundamental na construção de valores, conceitos e atitudes que contribuem para que a relação homem-natureza ocorra de forma responsável e consciente. Vale ressaltar que as concepções de natureza variam bastante, pois cada indivíduo tem uma forma particular de conceber o meio ambiente e de compreender as relações que estabelece com ela (WEIS, 2017).

A compreensão a respeito da maneira como cada sujeito percebe, vê, lê e interpreta o meio em que vive é fundamental para o educador, pois é dele a responsabilidade de mediar o conhecimento do sujeito ecológico em formação, repensando e reinterpretando as mudanças e transformações ocorridas no meio. Partindo do contexto do aluno se podem trabalhar suas relações com o ambiente de forma a desenvolver além de suas capacidades cognitivas a sensibilidade afetiva para a construção de um posicionamento ético diante do meio (NASCIMENTO; ZANON, 2018).

Partindo das considerações de Tardif (2000, p. 33-34), ao identificar e definir os saberes presentes na prática docente como plurais, por serem provenientes da formação profissional (o conjunto de saberes transmitidos pelas instituições de formação de professores), dos saberes disciplinares (que correspondem aos diversos campos de conhecimento e aos valores advindos da tradição cultural), curriculares (programas escolares) e experienciais (do trabalho cotidiano), percebe-se que essa multiplicidade de saberes exige do professor capacidade de dominá-los, integrá-los e mobilizá-los, enquanto condição fundamental para o exercício de sua atividade no ambiente escolar.

No entanto, analisando o decorrer da história, compreende-se que quando os portugueses desembarcaram no Brasil, encontraram com uma floresta densa e rica em recursos naturais. Os povos que aqui viviam, foram chamados de índios, tinham suas culturas, línguas, tradições e costumes bem definidos, vivia uma relação harmoniosa com a natureza (WEIS, 2017).

Nesse contexto, é grande a responsabilidade da escola que precisa ser reinventada para adequar-se ao seu papel na formação de um novo e verdadeiro cidadão. Cada aluno deve ser motivado para perceber, refletir e praticar ações que são urgentes para garantir a sustentabilidade do planeta, colocando-o em seu papel de cidadão consciente e transformador, corresponsável por difundir atitudes coerentes e responsáveis com o meio ambiente (COLOMBO, 2014).

Entretanto, a cultura indígena foi sendo cada vez mais influenciadas pelos colonizadores que tentaram implantar na tradição do índio nativo, a cultura europeia, seus costumes, vestimentas, educação, religião e até mesmo a culinária. Vale ressaltar que o os indígenas ao longo dos anos estabelecidos uma relação com a natureza onde o respeito para com a terra tem sido pautado nas trocas de reciprocidade, ou seja, eles retiram da natureza o sustendo, os alimentos necessários para sua sobrevivência, mantendo assim com o meio ambiente uma relação harmoniosa e de equilíbrio, que faz com que suas ações não sejam apenas de exploração, ao contrário da relação de dominação que ocorre com os chamados "brancos" (WEIS, 2017).

Porém, o que se percebe atualmente é que algumas culturas indígenas estão sendo influenciadas pelo estilo de vida da sociedade contemporânea, com luz elétrica, água encanada, internet, fato este que contribui na maioria das vezes para o enfraquecimento das culturas, ou seja, o índio moderno luta para manter sua herança cultural e de subsistência em meio à sociedade capitalista atual (COHN, 2001).

Os problemas ambientais considerados pelos professores como mais emergentes são: a poluição dos rios e das nascentes provocadas pelos esgotos e resíduos sólidos (lixo), o desmatamento, a queimada em geral e a constante destruição de fauna e flora. Ou seja, entre os docentes mais uma vez predomina uma visão naturalista do meio ambiente, pois, perguntadas quais seriam os problemas mais emergentes que a educação ambiental deveria trabalhar, elas insistiram em citar os problemas causados pelo homem (AZEVEDO; FERNANDES, 2010).

De fato, a natureza apresenta uma riqueza diversificada em seu ecossistema, em virtude disso, são retiradas quantidades expressivas de uma série de materiais, alimentos, recursos e produtos naturais sem o correto manejo de algumas matérias-primas, assim corremos o risco de tornar estes recursos naturais cada vez mais escassos, uma vez que a natureza não consegue se recompuser diante do alto padrão de consumo (COHN, 2001).

Segundo Fernandez et al. (2002), a educação e a percepção ambiental despontam como armas na defesa do meio natural e ajudam a reaproximar o homem da natureza, garantindo assim um futuro com mais qualidade de vida para todos.

Nesse sentido, Ventura (2009) afirma que a percepção ambiental supõe a capacidade que o ser humano possui de gerar informações a partir dos impactos ambientais que constituem seu cotidiano e a partir dessa produção, o ser humano conhece seu ambiente e é capaz de, sobre ele, produzir significados e ações. Sendo assim é a partir da formação de laços afetivos positivos é que pode acontecer a modificação dos valores atribuídos pelas pessoas para cada lugar em seu entorno (LIMA, 2003).

Portanto, os saberes indígenas respondem às suas necessidades e desejos, suas crenças, valores, tecnologias etc. provêm de um conhecimento comunitário prático e profundo gerado a partir de milhares de anos de observações e experiências empíricas que são compartilhadas e orientadas para garantir a manutenção de um modo de vida específico (SANTOS, 2006).

A escola é historicamente o espaço de sociabilidade do saber humano e, portanto, aí ele pode ser construído, transformado e transmitido com e na ação humana. Tal ação é que possibilita ao docente, de modo sistemático, difundir uma pluralidade de saberes e que, potencialmente, demanda a participação consciente de cada um dos sujeitos que vivenciam esse processo. Pressupõe, assim, uma ação articulada entre os sujeitos que agem e pensam, num espaço e num tempo, estabelecendo um 
significado de homem, de cultura e de ambiente (AZEVEDO; FERNANDES, 2010).

\section{Impactos Ambientais que afetam as Comunidades Indígenas}

Diversos têm sido os enfrentamentos entre as comunidades indígenas e os impactos socioambientais no que tange as grandes obras e a demarcação dos territórios indígenas. Inúmeras são as obras que vêm agregadas ao desenvolvimento econômico em âmbito local e regional que tem repercutido diretamente na configuração das terras nativas. Os impactos advêm da falta de diálogo, dos contratos comerciais obscuros, da inconstância acerca da delimitação e perda dos territórios, burocracia, bem como da violência simbólica e física acometida contra os povos indígenas (WENCZENOVICZ; DE MARCO, 2018).

É evidente que os problemas ambientais intensificavam-se cada vez mais, diante disso, diversas iniciativas revelam a preocupação com o futuro do planeta, provocando assim reflexões e discussões em níveis mundiais, onde se faz necessário o desenvolvimento de novas técnicas de conservação e prevenção do ecossistema natural.

No entanto, o agravamento dos problemas ambientais resultantes das atividades humanas na atualidade, segundo Marcondes (2005), aumentou de modo significativo, especialmente a partir da revolução industrial, quando o homem passou a produzir em grande escala e poluir na mesma proporção.

Verificaram-se, ao longo das últimas décadas, avanços significativos em relação à legislação ambiental e à conscientização preservacionista, por meio da educação, também constatamos que esses movimentos e ações não estão sendo suficientes para fazer frente à degradação ambiental em curso, visto que a abrangência do dano e dos desequilíbrios ambientais é bem superior à nossa capacidade social de controle. Nesse prisma, a educação ambiental, como tema transversal no currículo das escolas, proposta como prática pedagógica nos PCN's pode ser uma mediação importante para contribuir na reversão desse quadro de degradação e desequilíbrio do meio ambiente (AZEVEDO; FERNANDES, 2010).

Vale ressaltar que muitos desses problemas são consequências das ações transformadoras do ser humano sobre o espaço, nesse sentido destaca-se a excessiva exploração da natureza, empobrecimento do solo, desigualdades sociais, miséria, contaminação das águas, poluição atmosférica, perda da diversidade biológica, desmatamentos, construção de usinas hidrelétricas entre outros fatores que contribuíram para a degradação do meio ambiente.

Nesse sentido, a implantação de usinas hidrelétricas acarreta uma série de problemas as comunidades tradicionais fato este que tem gerado grandes discussões e muita repercussão sobre seu processo de implementação, visto que ocasionam grandes impactos ao meio ambiente e consequentemente no modo de vida e cultura das populações indígenas que usufruem da natureza para sua subsistência.

Lembrando que a partir do momento que as popu- lações tradicionais deixarem de ter acesso à sua área de preservação sendo obrigado a sair do seu território, o que ocorre não é somente uma violação do direito à vida, mas também à integridade pessoal, ficando assim impossibilitados de viver de acordo com sua cultura. Assim, diante desse aspecto fica evidente a urgência da criação de políticas públicas que realmente ofereçam assistência a essas populações para que os seus direitos não sejam violados.

Ao analisar os saberes docentes sobre a questão ambiental, será possível entender os possíveis caminhos de sua prática social e pedagógica, e conhecer as concepções que possuem e como agem em relação aos problemas ambientais, no contexto local e escolar. É nesse contexto que a Educação Ambiental ensinada na escola constitui-se como uma possibilidade de contribuir para uma educação de qualidade, garantindo o respeito à vida e a todos os cidadãos que partilham dessa realidade que se vive hoje (AZEVEDO; FERNANDES, 2010).

Garantir a sustentabilidade do planeta implica em mudanças de comportamentos e atitudes. Para que isso ocorra, a educação ambiental torna-se fator necessário e imprescindível. Conscientizar sobre a necessidade de novas condutas e posturas diante dos dilemas ambientais, coerentes com o que propõem os PCN's, exige que a escola garanta aos alunos situações em que possam pôr em prática sua capacidade de atuação (COLOMBO, 2014).

Os direitos estabelecidos na Lei de Diretrizes e Bases de 1996 e nas legislações subsequentes enfatizam que a educação indígena deverá ter um tratamento diferenciado em relação às outras escolas do sistema, determinado pela prática da interculturalidade e bilinguismo, porém esses encaminhamentos, além de não estarem bem discutidos e compreendidos, estão distantes de se efetivar na prática, vários são os entraves burocráticos que adiam o cumprimento da legislação (BURATTO, 2007).

Uma possível solução e/ou caminhos, seria a implementação da Sala Verde, que teve origem na Diretoria de Educação Ambiental do Ministério do Meio Ambiente (DEA/MMA). Seu objetivo é promover o incentivo para implantação de espaços socioambientais pelo país, instituindo Centros de Informação e Formação Ambiental, bem como potencializar espaços, estruturas e iniciativas similares já existentes em diversas instituições, por exemplo, órgãos públicos, privados e do terceiro setor. A sala verde é um ambiente dinâmico, nela, acontecem leituras, acesso e vista de documentos, participação de atividades educacionais e na promoção dos eventos, além de outras atividades (SANTOS; ESTEVES; SILVA, 2013).

\section{Conclusões}

A educação ambiental pode mudar hábitos e formas mais conscientes de seus atos e, principalmente transforma-os em multiplicadores de ações importantes para a preservação do meio ambiente em que vivem, uma vez que os povos indígenas são detentores de conhecimentos tradicionais milenares que necessitam serem cada vez mais valorizados, reconhecidos e inseridos nos processos 
educativos da educação escolar da sociedade envolvente e na educação ambiental. O estudo sobre a percepção ambiental, neste sentido, permitirá compreender como os professores indígenas adquirem conhecimentos, valores e como desenvolvem ações de sensibilização frente as questões ambientais. Diante disso, através dos dados coletados a pesquisa verificou-se a possibilidade na elaboração de propostas que venham envolver as comunidades indígenas, visando assim mudanças positivas que contribuam para conservação do patrimônio cultural. Dessa forma, é possível concretizar a educação como formadora de valores éticos e de cidadania.

\section{Agradecimentos}

Agradecimentos aos revisores, colaboradores e agência de fomento (FAPEAM).

\section{Referências}

AZEVEDO, D. S.; FERNANDES, K. L. F. Educação Ambiental na Escola: um estudo sobre os saberes docentes. Educação em foco, v. 14, n. 2, p. 95-119, 2010.

BRASIL. Secretaria de Educação Fundamental. Parâmetros Curriculares Nacionais: meio ambiente, saúde/Secretaria de Educação Fundamental. Brasília, 1997. $128 \mathrm{p}$.

BRASIL. Conselho Nacional de Educação. Câmara de Educação Básica. Diretrizes Curriculares Nacionais da Educação Escolar Indígena. Parecer 14/99, aprovado em 14/09/1999.

BURATTO, L. G. A educação escolar indígena na legislação e os indígenas com necessidades educacionais especiais. Universidade Estadual de Londrina. 2007.

CARVALHO, I.C.M. Educação ambiental: a formação do sujeito ecológico. 3. ed. São Paulo: Cortez, 2008.

COHN, C. Culturas em transformação: os índios e a civilização. São Paulo em Perspectiva, v. 15, n. 2, p. 36-42, 2001.

COLOMBO, S. R. A Educação Ambiental como instrumento na formação da cidadania. Revista Brasileira de Pesquisa em Educação em Ciências, v. 14, n. 2, p. 67-75, 2014.

DURKHEIM, É. Sociologia e filosofia. São Paulo: Martin Claret, 2009.

FAGGIONATO, S. Percepção ambiental. Disponível em: http://educar.sc.usp.br/biologia/textos/m_a_txt4.html. Acesso em: 20 out. 2007.
FAGGiONATO, S. Percepção ambiental. Material de apoio-textos. Projeto de Educação Ambiental. Disponível em: http:/educar. sc. usp. br/biologia/textos/ ma-txt4. html. Acesso em, 04 jan. 2016.

FATORELLI, L. Percepções sobre mudanças ambientais na Amazônia brasileira: caminhos para a construção de um conhecimento integrador. 2013. 246 f. Tese (Doutorado em Desenvolvimento Sustentável). Universidade de Brasília, Distrito Federal. 2013.

FERNANDEZ, R. S.; SOUZA, V. J.; PELISSARI, V. B.; FERNANDES, S. T. Uso da percepção ambiental como instrumento de gestão em aplicações ligadas às áreas educacional, social e ambiental. 2002. Disponível em: http://www.redeceas.esalq.usp.br/percepçãoambiental. pdf. Acesso em: 08 janeiro. 2018.

FERREIRA, M. R. Produção e conhecimento sobre degradação ambiental: uma incursão na psicologia ambiental. 1997. Tese (Doutorado em Psicologia Social). Pontifícia Universidade Católica, São Paulo.

FERREIRA, C. R. T. Avaliação da degradação urbana através da percepção ambiental: $O$ caso do alto da bacia do limoeiro, Presidente Prudente, SP. 2001. $102 \mathrm{f}$.

FREIRE, P. Pedagogia da autonomia: Saberes necessários à prática educativa. São Paulo: Paz e Terra, 1996.

FORGUS, R. H. Percepção: o processo básico do desenvolvimento cognitivo. São Paulo: Herder, 1971.

GIL, A. C. Como elaborar Projetos de Pesquisa. 4.ed. São Paulo, SP. Editora Atlas, 2008.

JACOBI, P. R. Educação ambiental, cidadania e sustentabilidade. Caderno de Pesquisa, n. 118, p. 189206, 2003.

JACOBI, P. R. Educação Ambiental: o desafio da construção de um pensamento crítico, complexo e reflexivo. Educação e Pesquisa, v. 31, n. 2, p. 233-250, 2005.

LIBÂNEO, J. C. Didática. $21^{\circ}$ reimpressão. São Paulo: Cortez, 1994.

LIMA, R. T. Percepção ambiental e participação pública na gestão dos recursos hídricos: perfil dos moradores da cidade de São Carlos, SP (Bacia Hidrográfica do Rio do Monjolinho). 2003. p 144.

MARCONI, M. A.; LAKATOS, E. M. Fundamentos de Metodologia Científica. 5.ed. São Paulo, SP. Editora Atlas, 2003. 
MARCZWSKI, M. Avaliação da percepção ambiental em uma população de estudante do Ensino Fundamental de uma escola municipal rural: um estudo de caso. 2006. Dissertação (Mestrado em Ecologia) - Instituto de Biociências, Universidade Federal do Rio Grande do Sul. Porto Alegre, 2006.

MACEDO, R. L. G. Percepção e Conscientização Ambientais. Lavras: UFLA - Universidade Federal de Lavras/ FAEPE - Fundação de Apoio ao Ensino, Pesquisa e Extensão, 2000.

MARCONDES, S. A. Brasil, amor à primeira vista! Viagem ambiental no Brasil do século XVI ao XXI. São Paulo: Editora Petrópolis, 2005.

MARIN, A. A. Pesquisa em educação ambiental e percepção ambiental. Pesquisa em Educação Ambiental. São Carlos; Sorocaba-SP: UFSCAR; Rio-Claro-SP: UNESP/ IBRC; Ribeirão Preto-SP: USP/FFCLRP, v.3, n.1, p.203222, jan/jun. 2008.

MORIN, E. Os sete saberes necessários à educação do futuro. 2. ed. São Paulo: Editora Cortez, 2000.

NASCimenTO, E. C. M.; ZANON, A. M. Percepção ambiental de professores indígenas Terena a partir de desenhos do meio ambiente. Revista Eletrônica Mestrado em Educação Ambiental, v.35, n.1, p. 229241, 2018.

NOGUEIRA, E. M. L.; PAES, L. R.; ALMIEIRA, J. A.; PERES, E. P. C.; MONTEIRO, A. C. A importância da educação ambiental para a formação emancipatória dos alunos do ensino fundamental frente às práticas docente. In: Anais... Congresso Nacional de Educação, 5, 2018; Recife (PE), Brasil. Recife, 2018.

OLIVEIRA, S. F. Educação Ambiental: aspectos históricos e perspectivas. Boletim Goiano de Geografia, v. 26, n. 2, p. 152-166, 2006.

OLIVEIRA, M. M. de. Como fazer pesquisa qualitativa. 4.ed. Petrópolis, Rj: Vozes, 2012.

PALMA, I. R. Análise da Percepção Ambiental como Instrumento ao Planejamento da Educação Ambiental. Dissertação de Mestrado, Programa de Pós-Graduação em Engenharia de Minas, Metalúrgica e de Materiais PPGEM, Universidade Federal do Rio Grande do Sul, 2005. 67p.

PENNA, A. G. Percepção e realidade: introdução ao estudo da atividade perceptiva. 3.ed. São Paulo: Mercurio Star, 1982.

PIAGET, J. Psicologia da inteligência. Brasil: Fundo de Cultura, 1967.
PINHÃO, F.; MARTINS, I. Diferentes Abordagens sobre o tema Saúde e Ambiente: Desafios Para O Ensino De Ciências. Ciência \& Educação, v. 18, n. 4, p. 819-835, 2012.

POTT, C. M.; ESTRELA, C. C. Histórico ambiental: desastres ambientais e o despertar de um novo pensamento. Estudos Avançados, v. 31, n. 89, p. 271-283, 2017.

REIS, R. S. Determinantes Ambientais para a Realização de Atividades Físicas nos Parques Urbanos de Curitiba: Uma Abordagem Sócio Ecológica da Percepção dos Usuários. 2001. Dissertação (Mestrado em Educação Física) - Centro de Desportos da Universidade Federal de Santa Catarina. Florianópolis, SC. 101 p.

ROSA, L. G.; SILVA, M. M. P. Percepção ambiental de educandos de uma escola do ensino fundamental. In: Anais... Simpósio Ítalo Brasileiro de Engenharia Sanitária e Ambiental, 6, 2002; Vitória (ES), Brasil. Vitória, 2002.

SANTOS, D. O. G. L. O Índio Brasileiro: o que você precisa saber sobre os povos indígenas no Brasil de hoje. LACED/Museu Nacional, 2006. 232 p.

SANTOS, E. S.; ESTEVES, L. U.; SILVA, T. L. Educação ambiental nas sociedades indígenas brasileiras: uma breve análise. Holos, v. 5, n. 29, p. 282-292, 2013.

SATO, M. Educação Ambiental. São Carlos: Rima. 2002.

SIQUEIRA, L. C. Política ambiental para quem?. Ambiente \& Sociedade, v. 11, n. 2, p. 425-437, 2008.

TARDIF, M. Saberes docentes e formação profissional. Petrópolis, RJ: Vozes, 2002.

VENTURA, A. da. C. Um contributo para o estudo das alterações climáticas: entre os discursos, as percepções dos riscos e as práticas quotidianas numa amostra da população da freguesia de Alcântara. Instituto Superior de Ciências Sociais e Políticas. Universidade Técnica de Lisboa. (Dissertação para obtenção de grau de Mestre em Antropologia). Lisboa, 2009. 183 p. Acesso em 20/02/2018.

VIANA, A.L.; LOPES, M. C.; NETO, N. F. A.; KUDO, S. A.; GUIMARÃES, D. F. S.; MARI, M. L. G. Análise da percepção ambiental sobre os parques urbanos da cidade de Manaus, Amazonas. Revista Monografias Ambientais, v. 13, n. 5, p. 4044-4062, 2014.

VIEIRA, F. C. B.; KALHIL, J. B.; RUIZ, M. A. Percepção ambiental: contribuições e práticas indígenas para o ensino de ciências no baixo Rio Negro. Fórum Ambiental da Alta Paulista, v. 8, n. 10, p.1-10, 2012.

WEIS, B. M. C. Relação cultural dos povos tradicionais indígenas com o meio ambiente e a sustentabilidade. Revista Direito e Humanidades, v.3, p.17-23, 2017. 
WENCZENOVICZ, T. J.; DE MARCO, C. M. Lições de 'Buen Vivir': impactos ambientais sobre as comunidades indígenas no Brasil contemporâneo. Revista Brasileira de Direito, v. 14, n. 2, p. 198-212, 2018.

\section{Contribuição dos autores}

Albanice de Souza Ramos

Contribuições substanciais para a concepção do trabalho; redigiu o trabalho e realizou uma revisão substancial.

Carlos Alexandre Santos Querino

Contribuições substanciais para a concepção do trabalho; redigiu o trabalho e realizou uma revisão substancial.

\section{Eulina Maria Leite Nogueira}

Contribuições substanciais para a concepção do trabalho; redigiu o trabalho e realizou uma revisão substancial.

Renato Abreu Lima

Contribuições substanciais para a concepção do trabalho; redigiu o

trabalho e realizou uma revisão substancial. 